\title{
Fertilization efficiency and gamete viability in the ascidian Pyura praeputialis in Chile
}

\author{
Patricio H. Manríquez ${ }^{1, *}$, Juan Carlos Castilla ${ }^{2}$ \\ ${ }^{1}$ Instituto de Biología Marina ‘Dr. Jürgen Winter' and Laboratorio Costero de Recursos Acuáticos de Calfuco, \\ Facultad de Ciencias, Universidad Austral de Chile, Casilla 567, Valdivia, Chile \\ ${ }^{2}$ Departamento de Ecología, Facultad de Ciencias Biológicas and Center for Advanced Studies in Ecology and Biodiversity, \\ Facultad de Ciencias Biológicas, Pontificia Universidad Católica de Chile, Casilla 114-D, Santiago, Chile
}

\begin{abstract}
In Chile, the ascidian Pyura praeputialis is an introduced species that occurs in intertidal and subtidal habitats restricted to Antofagasta Bay where it commonly forms extensive colonies that dominate mainly the rocky intertidal. Here we report the results of laboratory experiments conducted to determine the patterns of gamete spawning, and the consequences of the mode of reproduction, sperm age and sperm concentration on fertilization success. Our laboratory experiments indicate that the synchronous release of gametes takes place after the specimens are exposed to air, which is then followed by the formation of a biofoam in the rearing containers. Self fertilization with gametes obtained either by stripping or natural spawning failed to produce larvae or normal development, which occurred only when allosperm were used. Under laboratory conditions, fertilization success significantly decreased with sperm age and sperm concentration. Under field conditions, we recorded a negative effect of distance from areas with biofoam associated with spawning individuals on fertilization success. These findings suggest that it is selectively advantageous for this broadcast species to release gametes at low tide or after a period of emersion followed by biofoam formation. We suggest that this mechanism might have evolved to mitigate the difficulties of fertilization in turbulent aerated seawater, and to maximize fertilization success of short-lived gametes.
\end{abstract}

KEY WORDS: Broadcast spawner - Gamete longevity · Sperm concentration · Reproductive success · Synchronous spawning $\cdot$ Biofoam $\cdot$ Ascidian

\section{INTRODUCTION}

Numerous sedentary marine invertebrate species that broadcast gametes into the water column (i.e. broadcast spawning) increase fertilization success through the synchronous spawning of eggs and sperm by individuals within a population (see Yund 2000). This phenomenon, which is described as 'a considerable number of individuals spawning in close proximity both temporally and spatially', has been reported for echinoderms, sponges, polychaetes, scleractinian corals, ascidians and molluscs (Babcock et al. 1992, Fan \& Dai 1995, Bingham 1997, Counihan et al. 2001). Regardless of the mode of reproduction (self fertilization versus cross fertilization), the patterns of gamete release in a free-spawning species have important consequences for sperm availability and fertilization success in marine broadcast species (Levitan et al. 1991, 1998a,b, Marshall 2002, Marshall et al. 2004).

Pyura praeputialis is a large ascidian that forms aggregated colonies that do not share common vascular systems (Pérez-Portela et al. 2009). It is an introduced species (Castilla et al. 2004) that is confined to the low intertidal and shallow subtidal rocky habitats within Antofagasta Bay (Castilla et al. 2002a, 2004). The synchronised mass spawning of intertidal populations of $P$. praeputialis during low tides is suggested to have evolved to increase fertilization success in this freespawning, simultaneous hermaphroditic species (Castilla et al. 2007). Our $6 \mathrm{yr}$ of field observations in 
Antofagasta, which were mainly concentrated during daytime low tides, indicate that the initiation of spawning in this ascidian takes place during the spring and summer seasons. Moreover, spawning has always been recorded only once the individuals have become exposed to air during daytime low tides (authors' pers. obs.; see Fig. 1). Although numerous environmental cues can be involved in the regulation of spawning synchrony, the spawning in the field described above suggests that spawning in P. praeputialis is initiated and synchronized by exposure to air during low tides. This is reinforced by observations of $P$. praeputialis (Castilla et al. 2007) and of another tunicate Pyura stolonifera (Marshall 2002), which suggest that exposure to air during low tides is the mechanism that promotes synchronised spawning; exposure could therefore have significant consequences for improving fertilization success in free-spawning ascidians. However, the tidal cycle and differences in water depth have also been suggested in the literature as mechanisms responsible for triggering the onset of synchronous spawning (Watson et al. 2000), which cannot be disregarded as further potential cues for gamete release. Since fertilization success is a key element in maximizing fitness, the objectives of the present study were to investigate (1) the role of air exposure as a mechanism involved in promoting synchronised spawning in P. praeputialis, and (2) the consequences of the mode of reproduction, gamete longevity and gamete concentration on fertilization success. Since the spawning of gametes in P. praeputialis decreased seawater surface tension and induced the formation of biofoam (Castilla et al. 2007), we hypothesized that eggs immersed in seawater obtained from areas with and without biofoam (i.e. visual manifestation of gamete suspensions) should produce contrasting levels of fertilization success.

\section{MATERIALS AND METHODS}

Study organism. Adult specimens of Pyura praeputialis were collected during low tides from rocky intertidal platforms at Quebrada El Way $\left(23^{\circ} 45^{\prime} \mathrm{S}, 70^{\circ} 26^{\prime} \mathrm{W}\right)$ and Automóvil Club de Antofagasta $\left(23^{\circ} 42^{\prime} \mathrm{S}, 70^{\circ} 25^{\prime} \mathrm{W}\right.$ ) on several occasions between 2003 and 2005. After collection, the specimens were immediately transported to the Estación Costera de Investigaciones Marinas (ECIM) in Las Cruces $\left(32^{\circ} 43^{\prime} \mathrm{S}, 71^{\circ} 38^{\prime} \mathrm{W}, \sim 1500 \mathrm{~km}\right.$ to the south, in central Chile), where all the experiments were conducted. In the laboratory, the specimens were maintained under natural photoperiod in an $800 \mathrm{l}$ rearing tank, with recirculated and aerated seawater at temperatures ranging from 13 to $17^{\circ} \mathrm{C}$. To comply with Chilean laws and avoid the accidental introduction of the species into an area where they are not present, the waste seawater was mixed with tap water and drained through PVC pipes into a hole in the ground $30 \mathrm{~m}$ away from the high tide level. In the laboratory, the ascidians were fed with cultured microalgae (Isochrysis galbana and Chaetoceros calcitrans). Published rearing protocols (Strathmann 1987) were followed: morbid specimens were removed daily and the specimens were kept above the bottom of the tank to provide adequate water circulation and reduce the accumulation of detritus and faeces.

Expt 1. Effect of immersion-emersion on gamete release. The experimental set-up consisted of 2 Plexiglas aquaria (60 $\mathrm{cm}$ wide, $30 \mathrm{~cm}$ high and $80 \mathrm{~cm}$ long) that were placed on top of a $300 \mathrm{l}$ tank filled with UVtreated and $1 \mu \mathrm{m}$ filtered seawater. Six adult specimens of Pyura praeputialis were placed in each aquarium and allowed to acclimatize in running seawater for a 48 $\mathrm{h}$ period. The same experimental set-up was used to run 8 different experimental replicates with 6 ind. each. During acclimation, all the experimental individuals were completely submerged. Two contrasting treatment conditions were applied: (1) an aquarium in which the specimens were maintained under continuous immersion for an additional period of $12 \mathrm{~h}_{i}$ and (2) an aquarium in which the specimens were exposed to 6 successive cycles of immersion-emersion (each lasting $10 \mathrm{~min}$ ) for a period of $1 \mathrm{~h}$, followed by continuous immersion. During the experiments, seawater temperature ranged from 13 to $18^{\circ} \mathrm{C}$ (within the range found in Antofagasta Bay; Castilla et al. 2002b) and the aquaria were maintained in a darkened room. In each experimental run, the first 2 samples were taken during the final hours of the acclimation period. Then, after each immersion-emersion cycle, samples were taken from each treatment every $30 \mathrm{~min}$. Samples of eggs, sperm and tadpole larvae were taken from the seawater flowing out of the aquaria using a $50 \mu \mathrm{m}$ mesh sieve, the lower end of which was submerged to prevent damage to the samples. The filtered seawater was then returned to the reservoir. The mesh size was fine enough to retain the eggs, developing embryos and tadpole larvae but large enough to allow the passage of sperm. The sieve was replaced with a clean one after each sampling. Eggs and developing embryos were removed from the mesh, placed in a glass Petri dish and counted under a stereomicroscope. Counts were expressed as number per specimen and volume of seawater sampled from the aquarium during the sampling period (30 min). Sperm counts (see Manríquez et al. 2001, Manríquez \& Castilla 2005) were made from $20 \mathrm{ml} \mathrm{sam-}$ ples collected every $30 \mathrm{~min}$ from the container in which the sieve was submerged. Spawning episodes during the experiment were counted, assigned to the immersion or emersion phase of each cycle, averaged and expressed as a function of elapsed time. Similarly, gamete 
counts from each of the 8 trials were averaged and expressed as a function of elapsed time. At the end of the experiment, all adult specimens were dissected to assess their reproductive stage and to determine whether or not they were spent.

Expt 2. Mode of reproduction under laboratory and field conditions. In the laboratory, we manipulated self and cross fertilization by using both sperm and latedeveloping eggs stripped from adults. When sperm and late-developing eggs were detected simultaneously in the gonoducts of the same specimen, 2 batches of eggs were removed from each donor specimen. Subsequently, each batch of 400 eggs was exposed in a Petri dish to either selfsperm or allosperm removed from another donor specimen, at a concentration that did not limit fertilization in Pyura praeputialis (see 'Results: Expt 4'). As a control for sperm contamination, an extra group of eggs was maintained in $0.45 \mu \mathrm{m}$ filtered and $24 \mathrm{~h}$ aged seawater (hereafter FSW). Based on the availability of experimental specimens, this experiment was conducted 3 times with 4 different pairs of gamete donor/recipient (12 replicates). We ran 2 experimental series using the same specimens first as sperm donors and then as sperm recipients. The gamete solutions were incubated at $14 \pm 2{ }^{\circ} \mathrm{C}$ for $1 \mathrm{~h}$ and excess sperm was then removed with FSW. The eggs were then transferred to clean beakers filled with $100 \mathrm{ml}$ of FSW to assess fertilization success. In this experiment, fertilization success was determined as the proportion of eggs that developed into embryos and then into tadpole larvae or newly settled ascidians.

Under field conditions during low tides, we removed naturally shed sperm (see Fig. 1e) and eggs from the surface of adult specimens of Pyura praeputialis to conduct fertilization trials. Samples of eggs were removed from 10 ind., taking special care to avoid removing eggs that were in contact with sperm suspensions. In the trials, sperm suspensions that were spatially associated with specific egg masses were considered to be related gametes shed by the same individual. However, sperm suspensions that were not spatially associated ( > $1 \mathrm{~m})$ with egg masses were considered to be unrelated gametes. Twenty $1 \mathrm{ml}$ samples of egg masses ( 5000 eggs) were placed in individual $10 \mathrm{ml}$ plastic jars, added with FSW and supplied with a drop of dry sperm. To assess the effect on fertilization success of the spatial relatedness between sperm and eggs, 10 jars received related sperm and another 10 unrelated sperm. After $1 \mathrm{~h}$ of incubation, the fertilization process was stopped by the addition of $0.5 \mathrm{ml}$ of $40 \%$ formaldehyde. Once in the laboratory, 100 eggs were randomly selected, examined under a stereomicroscope, and recorded as fertilized or unfertilized. Since the development of tadpoles takes $>24 \mathrm{~h}$, the criterion for assessing successful cross-fertilization in the field experiment was the presence of eggs with a normal pattern of cleavage (Clarke et al. 1999), rather than the production of tadpoles (indicative of self fertilization). Eggs with no cleavage or with an abnormal cleavage pattern were considered unfertilized and polyspermatic, respectively.

Expt 3. Sperm concentration and fertilization success. To assess the effect of sperm concentration on fertilization success, we manipulated the cross fertilization of strip-spawned late-developing eggs by exposing them to strip-spawned allosperm suspensions of a similar age and at concentrations that did not limit fertilization (see 'Results: Expt 4'). Eggs (n = 300) from 4 different females were exposed to a range of concentrations $\left(10^{0}-10^{8}\right.$ sperm ml $\left.{ }^{-1}\right)$ for $1 \mathrm{~h}$ at $14 \pm 2^{\circ} \mathrm{C}$, with excess sperm being removed with FSW. Fertilization success in this experiment was evaluated using the protocol described above for laboratory fertilization. Following previous studies on the effect of sperm concentration on fertilization success in marine invertebrates (see McCartney \& Lessios 2002), we used linear regression of logit-transformed proportions of fertilized eggs on log transformed sperm concentration, and calculated $F_{50}$ as the sperm concentration at which $50 \%$ of the eggs were fertilized.

Expt 4. Sperm age, sperm concentration and fertilization success. To assess the effect of sperm age on fertilization success, we manipulated the cross fertilization of strip-spawned late-developing eggs by exposing them to strip-spawned allosperm suspensions. Batches of 50 freshly stripped eggs (mean egg diameter: $285.3 \pm 10.9 \mu \mathrm{m}$ SD) were exposed to stripspawned allosperm suspensions of known age: 0.33 , $0.5,1,2,4,6,12,24,36$ and $72 \mathrm{~h}$. Because we failed to find 4 ind. in which both gonads were mature, the experiments were conducted using a mix of 3 sperm donors and 4 egg donors. Stripped sperm were stored in ice and then diluted with FSW to achieve concentrations of $10^{8}, 10^{7}$ and $10^{6}$ sperm $\mathrm{ml}^{-1}$. The egg-sperm suspensions were incubated for $1 \mathrm{~h}$ at $14 \pm 2^{\circ} \mathrm{C}$ and excess sperm was then removed with FSW. Back-calculation from common regression of sperm age on decline in fertilization success with trailing zeros was used to assess sperm half-lifespan. Fertilization success in this experiment was evaluated using the protocol described above for laboratory fertilization.

Expt 5. Egg age and fertilization success. To evaluate the effect of egg age on fertilization success, we exposed strip-spawned eggs to allosperm suspensions at $0.33,0.5,1,2,4,6,12,24,36$, or $72 \mathrm{~h}$ following spawning. Strip-spawned eggs from 6 ind. were divided into 2 groups. The first group was maintained in a glass Petri dish (Treatment 1) and the second was used to create a 51 suspension of $0.1 \mathrm{egg} \mathrm{ml}^{-1}$ in a glass beaker (Treatment 2). Eggs were maintained at $14 \pm 2{ }^{\circ} \mathrm{C}$ and exposed $(n=100)$ to a 11 suspension of strip-spawned 
sperm of a known age (ranging from $0-8 \mathrm{~h}$ ) and at a concentration that did not limit fertilization $\left(10^{6} \mathrm{sperm}\right.$ $\mathrm{ml}^{-1}$ ). Treatments 1 and 2 were designed to imitate 2 natural spawning conditions (see Castilla et al. 2007) that occur when eggs are released: (1) the undiluted conditions on top of the spawning specimens or in the interstices between contiguous individuals, and (2) the diluted conditions when the sperm suspensions reach the surrounding seawater. Back-calculation from common regression of egg age on decline in fertilization success with trailing zeros was used to assess egg halflifespan. Fertilization success in this experiment was evaluated using the protocol described above for laboratory fertilization.

Expt 6. Simultaneous ageing of eggs and sperm and fertilization success. Under natural and laboratory conditions, Pyura praeputialis sheds male and female gametes simultaneously (Castilla et al. 2007); hence, the effect of the simultaneous ageing of both gamete types on fertilization success was evaluated in this experiment. A mix of 6 sperm donors and 6 egg donors was used. Eggs and sperm in suspension at concentrations of 0.1 egg ml-1 and $10^{6}$ sperm $\mathrm{ml}^{-1}$ were maintained at $14 \pm 2^{\circ} \mathrm{C}$. At $12 \mathrm{~min}$ intervals from 0 to $2.6 \mathrm{~h}$, $\sim 50$ eggs were removed and exposed to a 11 suspension of strip-spawned sperm. Following this protocol, eggs and sperm were of the same age at the time of mixing. Fertilization success in this experiment was evaluated using the protocol described above for laboratory fertilization.

Expt 7. Distance to the spawning site, biofoam and fertilization success. In natural populations of Pyura praeputialis and after the synchronised spawning, some of the shed gametes remain in the form of a viscous mass on top of spawning individuals; this viscous mass then develops into a biofoam (Castilla et al. 2007). Therefore, if spawning is not observed directly in the field, it is possible to distinguish areas on the shore where spawning has taken place by the presence of biofoam accumulations, which could be moved up-shore by the rising tide. Although it has yet to be proven, Castilla et al. (2007) suggest that the high abundance of developing embryos in biofoam areas is a result of the increased probability of contact between gametes retained in the biofoam compared to those in areas without biofoam. To assess how the fertilization success of $P$. praeputialis is affected by the presence of biofoam (i.e. different sperm availability) under natural conditions, we conducted additional experiments on the rocky intertidal platforms inhabited by this species in Antofagasta. These platforms are subdivided by narrow gaps or intertidal surge channels, which form intertidal pools and narrow inlets that are protected from wave action during low tides. This experiment was conducted with naturally shed and stripspawned eggs.
Naturally shed egg masses (mean egg diameter: $273.1 \pm 23.1 \mu \mathrm{m}$ SD, $\mathrm{n}=50$ ) were removed from the surface of the spawning individuals $(\mathrm{n}=10)$ using a plastic pipette. Egg suspensions were pooled and $1 \mathrm{ml}$ aliquots ( 5000 eggs) were deployed within small (80 ml) cages (100 $\mu \mathrm{m}$ mesh) that allowed the passage of sperm. Five individual cages were deployed along 2 transects at $0,2,4,8$, and $16 \mathrm{~m}$ from the spawning individual. Each cage was enclosed inside a $1 \mathrm{~mm}$ mesh bag, which was attached to the base of the ascidians by a $1 \mathrm{~m}$ long plastic line that allowed the cages to remain continuously immersed in seawater $(\sim 20-40$ $\mathrm{cm}$ below the surface). The first transect was directed up-shore away from the biofoam and the second was directed down-shore into the biofoam. The cages were exposed for a period of $30 \mathrm{~min}$ before being retrieved. Strip-spawned eggs were acquired by dissecting individuals $(\mathrm{n}=10)$ in the field (mean egg diameter: 261.90 $\pm 17.87 \mu \mathrm{m} S D, n=50$ ). Again, the egg suspensions were pooled and $1 \mathrm{ml}$ aliquots ( 5000 eggs) were deployed in cages that allowed the passage of sperm as described above. In this case, the groups of 5 cages were exposed to surface seawater samples $(\sim 10 \mathrm{~cm}$ depth) for $30 \mathrm{~min}$ in $1 \mathrm{l}$ plastic beakers. The water samples were taken at 2, 4, 8 and $16 \mathrm{~m}$ along 2 transects that were centred in the transition between biofoam and non-biofoam areas; the first transect was directed up-shore away from the biofoam, while the second was directed down-shore into the biofoam. As control groups to assess for unwanted (cross or self) fertilization, 5 independent groups of eggs were maintained in filtered and $24 \mathrm{~h}$ aged FSW, i.e. seawater without sperm, for a period of $30 \mathrm{~min}$. At the end of the exposure period, the eggs were removed from the cages and placed in $10 \mathrm{ml}$ plastic containers; the fertilization process was then stopped with the addition of $0.5 \mathrm{ml}$ of $40 \%$ formaldehyde. Once in the laboratory, 300 random eggs and developing embryos were observed under a stereomicroscope and designated as fertilized or unfertilized. Fertilization success in this experiment was evaluated using the protocol described above for field fertilization.

\section{RESULTS}

\section{Expt 1. Effect of immersion-emersion on gamete release}

Gametes were not found in the water samples that were removed during the final hours of the acclimation period (total immersion) before the start of the immersion-emersion cycle (see Fig. 2a,b). As under field conditions (Fig. 1a-c), gamete release was only recorded when specimens of Pyura praeputialis in the 

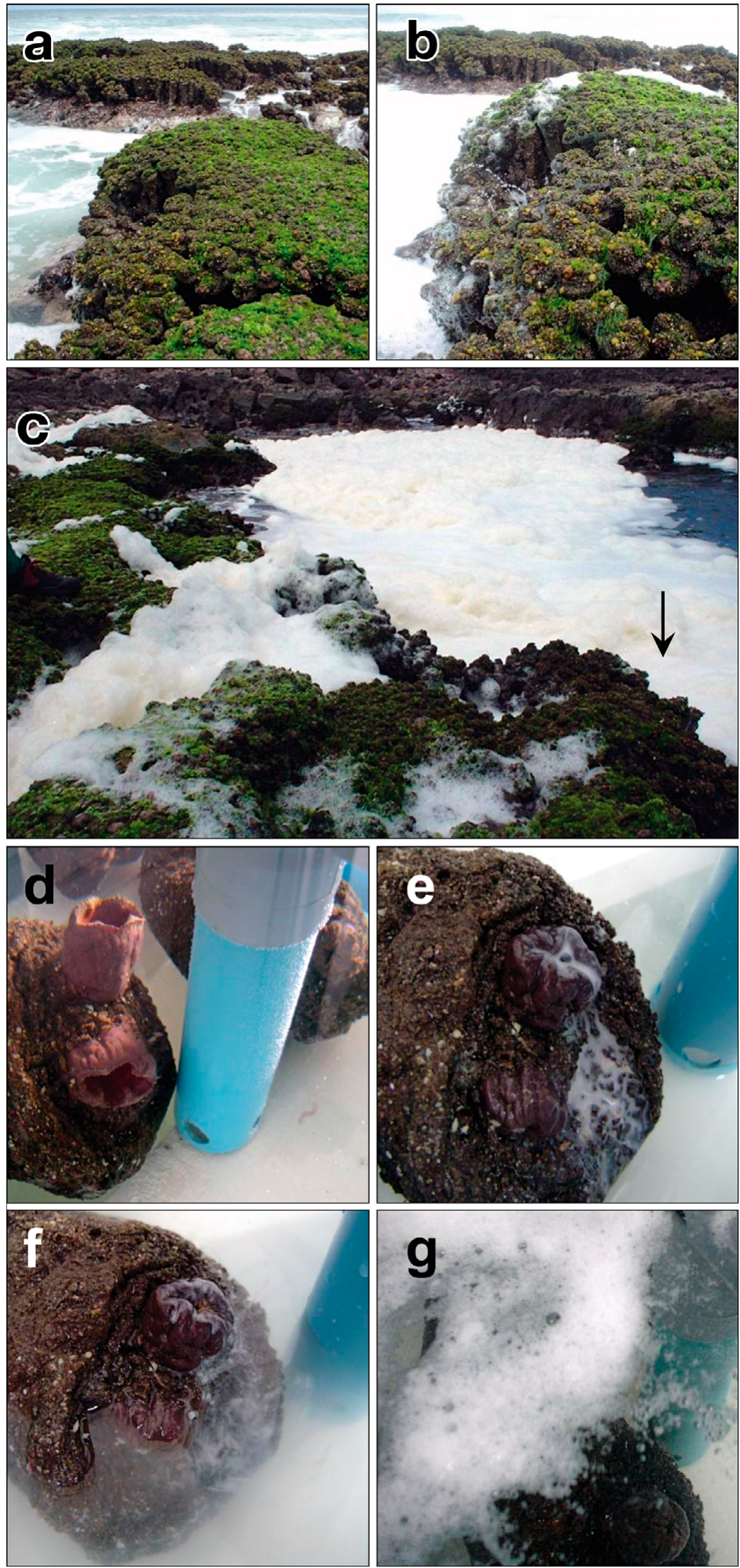

aquaria were exposed to air during the emersion phase of the cycle (Fig. 1d-g, Fig. $2 \mathrm{a}-\mathrm{c})$. Under these conditions, whitish suspensions of sperm (Fig. 1e) and strong olive-green egg masses were shed through the exhalant siphons. The first spawning events were more fluid, allowing the gamete suspension to cross the entire aquarium; however, the subsequent spawning events were less fluid, with the gamete suspension remaining on top of the spawning specimens and near the exhalant siphon. Egg suspensions were viscous masses that remained amalgamated for some time without apparent dissolution; however, sperm suspensions were more liquid and started to be diluted with the surrounding seawater almost immediately (Fig. 1f). Egg diameter ranged from 270 to $310 \mu \mathrm{m}$ (average: $287 \pm 10.55 \mu \mathrm{m} \mathrm{SD} ; \mathrm{n}=300$ ). Of the 48 ind. that were used in the immersion-emersion treatment, 37 $(77 \%)$ released both egg and sperm suspensions. The release of either sperm or eggs only was recorded in 3 $(6 \%)$ and $2(4 \%)$ ind., respectively. No gamete spawning was recorded in 6 ind. (13\%). Dissections conducted at the end of the experiments showed that specimens spawning gametes in the immersion-emersion treatment were totally spent. However, 4 of the 6 ind. that failed to spawn gametes were immature, while the other 2 were mature. In the alternative treatment with continuous immersion, no gamete spawn-

Fig. 1. Pyura praeputialis. Photographs before, during and after a spawning episode under $(\mathrm{a}-\mathrm{c})$ field and $(\mathrm{d}-\mathrm{g})$ laboratory conditions. (a) Section of a rocky intertidal platform at Antofagasta with several individuals before the spawning episode. (b) The same section with the presence of biofoam in the nearby seawater $1 \mathrm{~h}$ after spawning. (c) General view of the intertidal platform surrounded by biofoam $1 \mathrm{~h}$ after spawning; $(\longrightarrow)$ the rocky section photographed in (a) and (b). (d) Totally immersed specimen. (e) Totally emerged specimen with sperm suspension (whitish fluid) on its surface. (f) Beginning of the next immersion cycle with sperm being diluted by nearby seawater. (g) End of the immersion cycle with biofoam on top of the experimental aquarium 

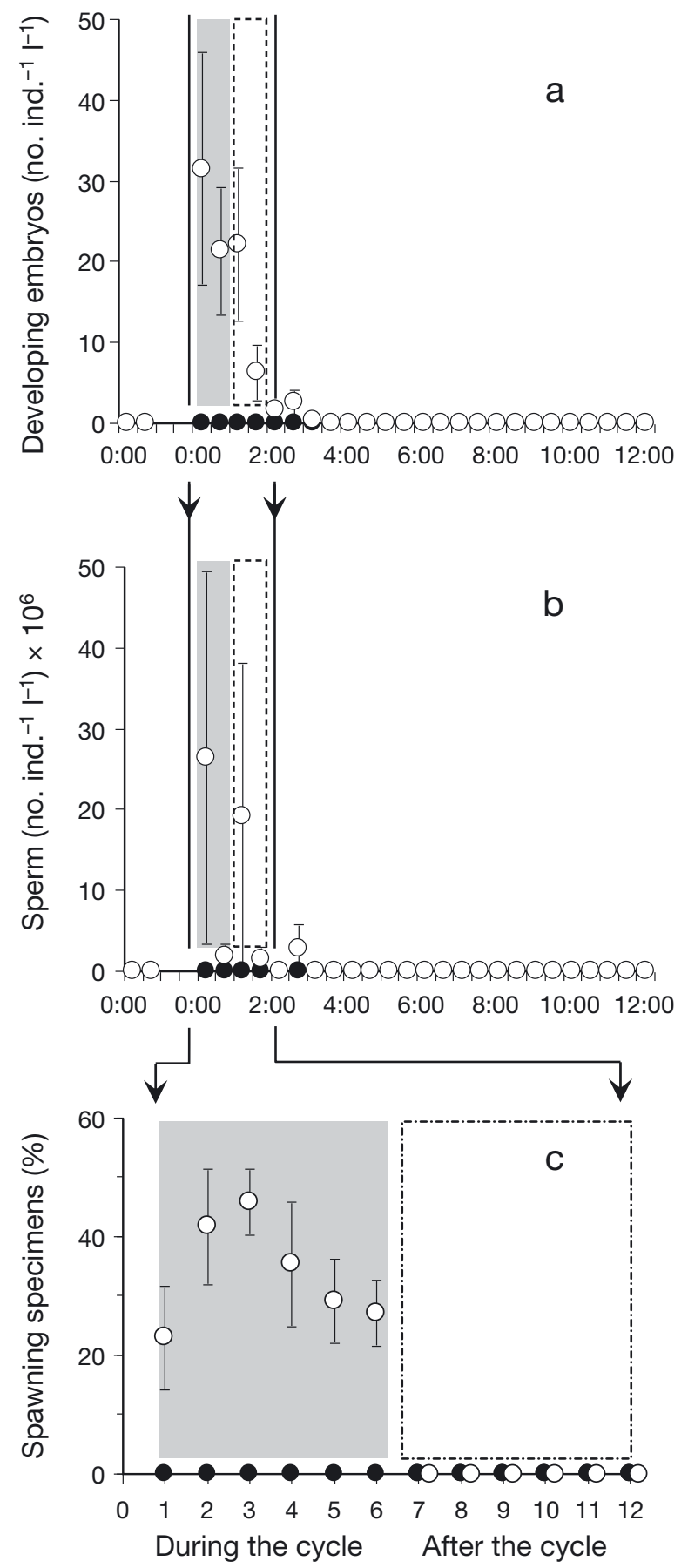

Fig. 2. Pyura praeputialis. Expt 1. Mean number $( \pm \mathrm{SE})$ of (a) developing embryos and (b) sperm standardized using the number of specimens and seawater volume recorded at regular intervals (30 min) under contrasting immersion-emersion conditions ( $\mathrm{n}=8$ aquaria with 6 ind. each). After $48 \mathrm{~h}$ of acclimatization in the experimental aquaria, the first 2 samples were taken and the specimens were then exposed to 6 successive 10 min cycles of immersion-emersion for a period of $1 \mathrm{~h}$ $(O)$ or maintained immersed under control conditions $(\bullet)$. In (c), the average percentage $( \pm \mathrm{SE})$ of spawning specimens during and after the immersion-emersion cycle are shown for treated $(O)$ and untreated specimens $(0)$ ing was recorded and the dissections of the specimens at the end of the experiments detected gonadal tissues with eggs and sperm in 34 of 48 ind. On numerous occasions, the sperm and egg suspensions remained on top of the spawning individuals, started to dissociate once the aquaria were filled with seawater, and formed a thick layer of biofoam (Fig. 1g). Further analysis of the sampled outflow indicated the presence of developing embryos and sperm only in samples from the aquarium with successive cycles of immersion-emersion (Fig. 2b) once the seawater carrying the biofoam reached the outflow level. Spawning individuals were observed only during the immersion-emersion cycle, and exclusively matching the emersion period. The average percentage of synchronously spawning individuals ranged from 20 to $50 \%$ (n = 8 aquaria with 6 ind. each, Fig. 2c). No spawning was observed when the ascidians were totally covered with seawater, either during or after the cycle (Fig. 2c). Dissection of specimens that failed to spawn revealed the absence of mature gametes in gonoducts. However, dissection of individuals that had spawned indicated that they were spent.

\section{Expt 2. Mode of reproduction}

No developing embryos or tadpole larvae were recorded with selfsperm or when the eggs were maintained in the control treatment of FSW only. In all experimental replicates conducted under laboratory conditions, viable developing embryos and tadpole larvae were only recorded when eggs were exposed to allosperm suspensions. On average, fertilization success was $71.3(\mathrm{n}=12 ; \mathrm{SE}=7.1)$ and $68.8 \%(\mathrm{n}=12 ; \mathrm{SE}=$ 8.7 ) in the first and second experimental series respectively. Under field conditions, the presence of normal developing stages was recorded in only 3 trials using spatially related sperm (average $6.9 \pm 3.9 \% \mathrm{SE}$ ). However, when unrelated sperm were used, the presence of normal developing stages was recorded in 9 trials (average $46 \pm 8.4 \% \mathrm{SE}$ ). Average fertilization success was significantly higher when unrelated sperm were used ( $t=-4.823$, df $=9, \mathrm{p}<0.001)$. Unfertilized eggs were recorded with both types of sperm. However, the average percentage of unfertilized eggs with spatially related sperm $(92.2 \pm 4.1 \% \mathrm{SE})$ was significantly higher (almost twice; $t=5.028$, df $=9, \mathrm{p}<0.001$ ) than that recorded with unrelated sperm $(42.3 \pm 8.9 \% \mathrm{SE})$. Eggs with abnormal development were recorded in every trial with spatially unrelated sperm but only in 2 trials with spatially related sperm. The average percentage of abnormal eggs was $0.9(\mathrm{n}=2$; $\mathrm{SE}=0.64)$ and $11.7 \%(n=10 ; \mathrm{SE}=3.04)$ for spatially unrelated and spatially related sperm, respectively. 


\section{Expt 3. Sperm concentration and fertilization success}

Fertilization success of Pyura praeputialis using strip-spawned gametes under laboratory conditions ranged between 0 and $84 \%$, following a linear relationship (Fig. 3). Maximum values of mean fertilization success were recorded when fresh sperm suspensions ranging between $10^{8}$ and $10^{6}$ sperm $\mathrm{ml}^{-1}$ were used (Fig. 3). A sperm concentration of $10^{3}$ produced a low fertilization success $(\sim 10 \%)$ and the lowest sperm concentration invariably failed to produce successful fertilizations (Fig. 3). The logit-transformed fertilization success data showed a good fit with log sperm concentration $\left(\mathrm{r}^{2}=0.88\right)$, and the estimated $F_{50}$ value was $10^{5}$ sperm $\mathrm{ml}^{-1}$.

\section{Expt 4. Sperm age, sperm concentration and fertilization success}

Fertilization success of Pyura praeputialis using strip-spawned gametes under laboratory conditions showed maximum mean values with fresh sperm suspensions (Fig. 4). This was observed with the 3 sperm concentrations used and no fertilization was recorded with sperm older than $36 \mathrm{~h}$. Sperm concentration significantly influenced the rate of decline in fertilization success with sperm age (ANCOVA on arcsine-transformed data, sperm age $\times$ time; $F_{2,116}=$ $19409, \mathrm{p}<0.001)$. The estimated sperm half-life back calculated from the regression indicated that sperm longevity increased $5 \times$ from 0.92 to $4.9 \mathrm{~h}$ when sperm concentration was increased from $10^{6}$ to $10^{8}$ sperm $\mathrm{ml}^{-1}$ (Fig. 4).

\section{Expt 5. Egg age and fertilization success}

Average fertilization success was significantly affected by egg age and dilution (Fig. 5, Table 1). The estimated egg half-life back calculated from the best regression equations indicated that egg longevity increased $6 \times$ from $0.59 \mathrm{~h}$ under dilute conditions to $3.6 \mathrm{~h}$ under undiluted conditions.

Fig. 4. Pyura praeputialis. Expt 4. Mean percentage $( \pm \mathrm{SE})$ of eggs developing through metamorphosis and settlement (fertilization success) as a function of the age of allosperm suspensions at (a) $10^{6}$, (b) $10^{7}$, and (c) $10^{8}$ sperm $\mathrm{ml}^{-1}$. Values of sperm half-life ( $\mathrm{HL}$ in $\mathrm{h}$; the time needed for fertilization to decrease to $50 \%$ of the initial number of eggs) were backcalculated from common best-fit logarithmic regression lines of sperm age and the decline in fertilization success at each sperm concentration. $(\longrightarrow$ ) Sperm concentrations at which $50 \%$ of the maximum values of fertilization success were achieved

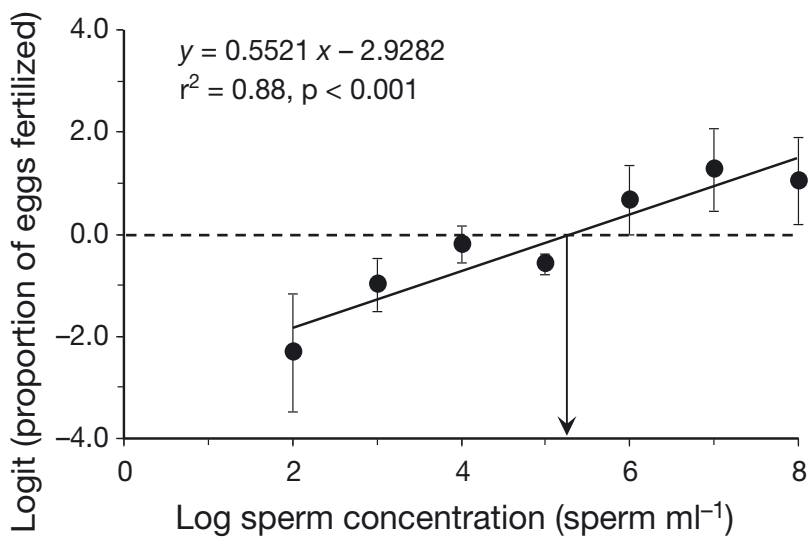

Fig. 3. Pyura praeputialis. Expt 3. Logit-transformed proportion of mean fertilized eggs $( \pm \mathrm{SE})$ as a function of log sperm concentration (sperm $\left.\mathrm{ml}^{-1}\right)_{i}(-)$ linear regression, $(\longrightarrow)$ the $F_{50}$ value showing the sperm concentration at which $50 \%$ of the eggs were fertilized
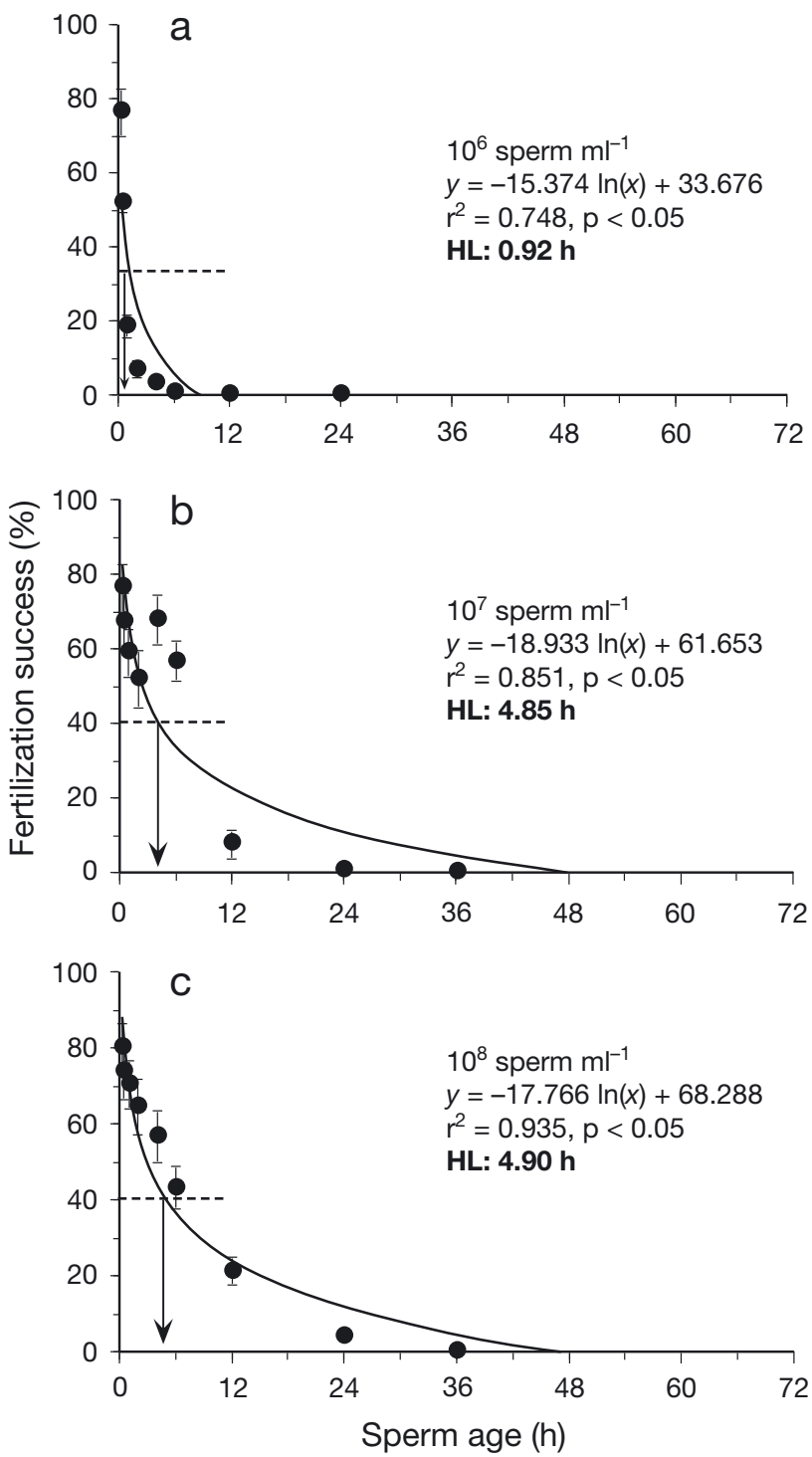


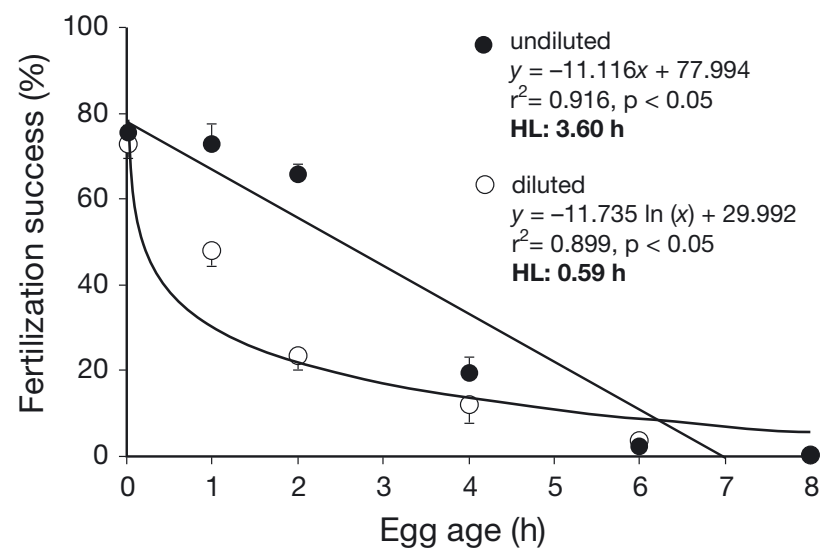

Fig. 5. Pyura praeputialis. Expt 5. Mean percentage $( \pm \mathrm{SE})$ of eggs developing through metamorphosis and settlement (fertilization success) as a function of egg age under 2 contrasting shedding conditions: undiluted aged eggs (Treatment 1) and diluted aged eggs (Treatment 2)

Table 1. Pyura praeputialis. ANCOVA comparing the fertilization success (\% arcsine transformed) of diluted and undiluted gamete suspensions at different gamete ages (Expt 5)

\begin{tabular}{|lccccc|}
\hline Source & SS & df & MS & $F$ & $p$ \\
\hline Dilution type & 0.345 & 1 & 0.345 & 20.13 & $<0.0001$ \\
Age & 7.168 & 5 & 1.434 & 83.68 & $<0.0001$ \\
Error & 1.045 & 61 & 0.17 & & \\
\hline
\end{tabular}

\section{Expt 6. Simultaneous ageing of eggs and sperm and fertilization success}

Fertilization success of Pyura praeputialis under laboratory conditions, using strip-spawned gametes of the same age at the time of mixing and at a concentration that did not limit fertilization $\left(10^{6}\right.$ sperm $\left.\mathrm{ml}^{-1}\right)$ ranged from 0 to $78 \%$ (Fig. 6). The estimated mixed gamete half-life back calculated from the regression indicated a longevity of $1.6 \mathrm{~h}$.

\section{Expt 7. Distance to the spawning site, biofoam and fertilization success}

In the experiment with naturally spawned eggs, fertilization success (evaluated as number of eggs with normal cleavage pattern) was $\sim 30 \%$. This figure is similar to the values of $\sim 40 \%$ recorded for eggs immersed in seawater with biofoam (Fig. 7a). Fertilization success was not dependent on distance from the spawning site $\left(n=25, r^{2}=0.002, p=0.834\right)$. However, when the eggs were immersed in seawater along the transect centred on the transition from the biofoam to

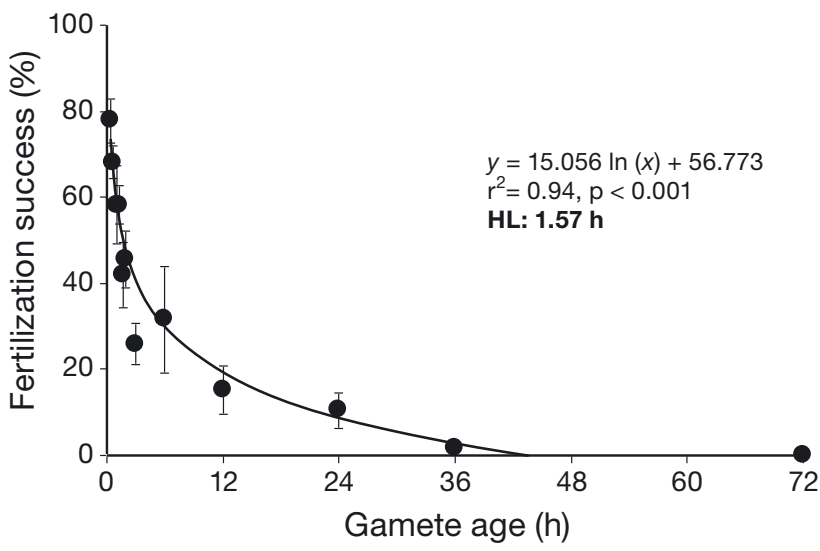

Fig. 6. Pyura praeputialis. Expt 6. Mean percentage $( \pm$ SE) of eggs developing through metamorphosis and settlement (fertilization success) as a function of the simultaneous ageing of sperm and eggs after strip-spawning. Sperm half-life (h) was computed as in Fig. 4

the non-biofoam areas, fertilization success was higher closer to the spawning site and depended on distance from the spawning site $\left(\mathrm{n}=17, \mathrm{r}^{2}=0.51, \mathrm{p} \leq 0.001\right)$. In the biofoam areas, eggs with abnormal cleavage patterns were represented at similar percentages $(\sim 50 \%)$, which were not dependent on distance from the spawning site $\left(\mathrm{n}=20, \mathrm{r}^{2}=0.010, \mathrm{p}=0.635\right)$. However, in the areas without biofoam, eggs with abnormal cleavage patterns were only found in the nearest site. In biofoam areas, the unfertilized eggs were represented by low and similar values $(\sim 5 \%)$ that were independent of the sampling site $\left(\mathrm{n}=20, \mathrm{r}^{2}=0.04, \mathrm{p}=\right.$ 0.338). However, in non-biofoam areas, the average percentage of unfertilized eggs increased significantly towards the end of the transect away from the spawning site. No fertilization was recorded in control eggs that were either exposed to aged seawater or immersed $>8 \mathrm{~m}$ away from the spawning site (Fig. 7a, Table 2).

In the second experiment using strip-spawned eggs, average fertilization success was significantly higher in eggs exposed to seawater from biofoam areas compared to those exposed to seawater from non-biofoam areas (ANOVA on arcsine transformed data: $F_{1,48}=$ $6.55, \mathrm{p}<0.001)$. As in the first experiment, fertilization success of the eggs immersed in biofoam seawater was also $\sim 40 \%$ and was independent of the sampling point ( $\mathrm{n}=12, \mathrm{r}^{2}=0.004, \mathrm{p}=0.787$ ). However, for eggs immersed in non-biofoam seawater, fertilization was low or nil, and was independent of the distance from the transition between the biofoam and the non-biofoam seawater $\left(n=12, r^{2}=0.59, p=0.0004\right)$ (Fig. $7 b$, Table 2). Eggs with abnormal cleavage patterns were not recorded in non-biofoam seawater, and were only recorded when eggs were immersed in biofoam areas, 
a

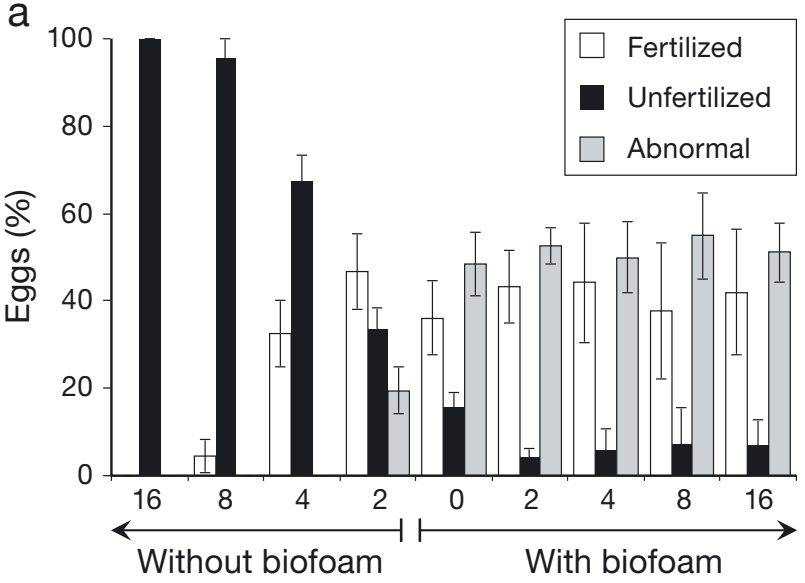

b

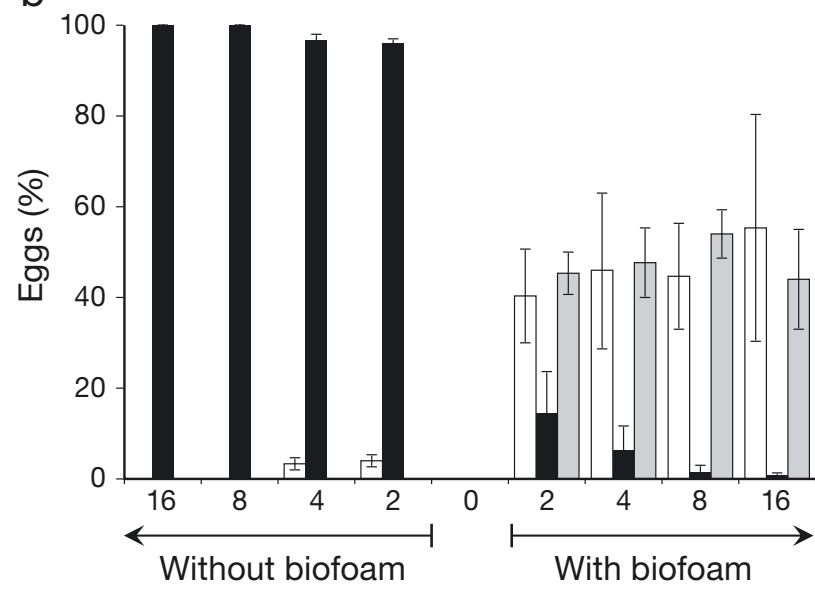

Fig. 7. Pyura praeputialis. Expt 7. Mean fertilization success, evaluated as \% eggs with normal cleavage pattern (open bars), unfertilized (black bars), or with abnormal cleavage pattern (gray bars) $( \pm \mathrm{SE})$, as a function of the linear distance along areas with and without foam. (a) Five groups of naturally spawned eggs immersed in seawater at different distances along up- and down-shore transects centred on the spawning site. (b) Stripspawned eggs immersed in seawater sampled at different distances along up- and down-shore transects centred on spawning individuals

Table 2. Pyura praeputialis. ANCOVA comparing the fertilization success ( $\%$ arcsine-transformed eggs with normal pattern of cleavage) of naturally spawned and strip-spawned eggs at different distances from the spawning site and along 2 seawater transects (biofoam and non-biofoam) (Expt 7)

\begin{tabular}{|c|c|c|c|c|c|}
\hline Source & SS & df & MS & $F$ & $\mathrm{p}$ \\
\hline \multicolumn{6}{|l|}{ Natural spawning } \\
\hline Distance & 0.904 & 1 & 0.904 & 17.13 & $<0.0001$ \\
\hline Type of seawater & 0.884 & 1 & 0.884 & 16.75 & $<0.0001$ \\
\hline Error & 2.482 & 47 & 0.03 & & \\
\hline \multicolumn{6}{|l|}{ Strip spawning } \\
\hline Distance & 0.0001 & 1 & 0.001 & 0.05 & 0.823 \\
\hline Type of seawater & 4.523 & 1 & 4.523 & 198.77 & $<0.0001$ \\
\hline Error & 0.842 & 37 & 0.023 & & \\
\hline
\end{tabular}

with average percentages $(\sim 50 \%)$ that were independent of distance along the transect (Fig. 7b). Although unfertilized eggs were present in both biofoam and non-biofoam seawater areas, average values were almost $15 \times$ lower in biofoam areas (Fig. 7b). Eggs that were immersed in FSW to test for unwanted (cross or self) fertilization only produced unfertilized eggs, suggesting that our results represent the consequences of sperm that were present in the experimental seawater.

\section{DISCUSSION}

The high proportion of spawning specimens of Pyura praeputialis during the experimental period of emersion supports previous field observations of synchronous spawning occurring during low tides in the same species (Castilla et al. 2007). Moreover, these observations concur with field reports of synchronized spawning in Pyura stolonifera, a congeneric species found along the southeast coast of Australia (Marshall 2002). Synchronous spawning during calm water has been recorded for other free-spawning marine invertebrates (Harrison et al. 1984, Babcock et al. 1986, Marshall 2002, Castilla et al. 2007), which suggests a common mechanism that has evolved in different groups to facilitate fertilization in a less turbulent, advective and dilutive environment. The release of gametes into slow flowing water with reduced turbulent mixing has also been recorded in terrestrial angiosperms (Culley et al. 2002), which suggests that the evolution of gamete release associated with optimal conditions for fertilization has a diverse phylogenetic origin.

After spawning, Pyura praeputialis gamete suspensions made contact with the nearby seawater or seeped into the gaps and pools between adjacent specimens. In these microhabitats during low tides, gamete suspensions (viscous mass) meet the conditions under which the chances for fertilization are highest (Meidel \& Yund 2001). Moreover, the importance of synchronous spawning under less dilutive conditions is supported by the observation that the lowest fertilization success was recorded for eggs immersed in non-biofoam nearshore seawater furthest from the spawning sites, suggesting the low availability of sperm in these areas. On the other hand, the high fertilization success and high percentages of eggs with abnormal cleavage patterns in the nearshore biofoam areas suggests the presence of high concentrations of sperm in these areas. Similar and higher values of fertilization success across biofoam than in non-biofoam areas suggest that sperm are evenly distributed there, although eggs with abnormal cleavage patterns (polyspermy?) are also higher in biofoam than in non-biofoam areas. Studies 
conducted with spermcast ascidians suggest that sperm availability declines with distance from the spawning point and is modified by depth and local hydrodynamic conditions (Yund et al. 2007). In our study, naturally shed eggs of $P$. praeputialis were immersed at approximately equal depths. However, the biofoam area was closer to the exposed face of the intertidal platform, and was thus subjected to the mixing of seawater, which could have contributed to a higher fertilization success in these areas. These suggest that our contrasting values of fertilization success under natural conditions may mainly be a consequence of sperm availability and distance from the spawning site, and has less to do with local hydrodynamic conditions. However, the confounding effects of differential hydrodynamic conditions and depth on fertilization success were not analyzed in the present study. Hence, future studies are needed to assess how fertilization success in $P$. praeputialis changes with depth and mixing (i.e. local hydrodynamic conditions).

Populations of Pyura praeputialis in Antofagasta inhabit intertidal and shallow subtidal habitats $(\sim 10 \mathrm{~m}$ depth). Therefore, spawning in subtidal populations cannot be explained by air exposure during low tides. However, depth differences between high and low tides are correlated with differences in hydrostatic pressure, which could act as an environmental trigger for synchronous spawning in subtidal populations of $P$. praeputialis as has been observed in lugworm polychaetes (Watson et al. 2000). Synchronous or nonsynchronous spawnings during total immersion were not recorded in our laboratory experiments. Moreover, since spawning during high tides is difficult to observe, we cannot hypothesize about their existence and magnitude. However, direct observations of spawning and biofoam aggregation just after the low tides suggest that intertidal spawning occurs once the ascidians are exposed to air. Synchronous spawning necessarily requires synchronization of gametogenesis, which should theoretically be associated with spring and summer seasons and higher seawater temperatures and food availability. Available information on nearshore surface temperatures in Antofagasta shows a clear seasonal and interanual pattern, with high temperatures during the summer season (Castilla et al. 2002b, Piñones et al. 2007). Similarly, chlorophyll a levels in the same area indicate higher levels of food availability during the same season (J. Castilla unpubl. data). Only 1 study (Gutiérrez \& Lay 1965) reported information on sexual maturity in $P$. praeputialis, and it provided evidence suggesting the existence of a seasonal reproductive cycle in this species. Gutiérrez \& Lay (1965) reported the presence of specimens with gonads in different developmental stages over almost the entire year, but with the highest percentages of specimens bearing fully mature gonads being mainly recorded during autumn and winter. Nevertheless, the presence of sexually mature specimens suggests that spawning in nature is biologically supported during almost the entire year. This is confirmed by the presence of biofoam near the intertidal platforms inhabited by $P$. praeputialis throughout the majority of the year (authors' pers. obs.).

The negative effects of both sperm age and concentration on fertilization success agree with other studies conducted with spermcast and broadcast marine invertebrates (Oliver \& Babcock 1992, André \& Lindegarth 1995, Baker \& Tyler 2001, Manríquez et al. 2001, Williams \& Bentley 2002, Pemberton et al. 2003). These negative effects have been attributed to the differential rate of oxygen consumption and energy expenditure at different sperm concentrations and ages (Chia \& Bickell 1983). A previous laboratory study (Clarke et al. 1999) indicated that after contact of the sperm of Pyura praeputialis with seawater, they remain active for $\sim 7-8 \mathrm{~h}$, which agrees with our results. The maximum sperm longevity recorded in our study was $36 \mathrm{~h}$ when sperm concentrations were between $10^{7}$ and $10^{8} \mathrm{ml}^{-1}$. These concentrations are similar to those recorded in Ascidia marina (Havenhand 1991). The levels of fertilization success in our study decreased drastically with sperm concentrations below $10^{4} \mathrm{ml}^{-1}$, which agrees with the data available for several broadcast spawning marine invertebrates (see Pemberton et al. 2003). However, most of the above-cited studies have not considered an extended period of egg longevity (Meidel \& Yund 2001, Yund et al. 2007). Nevertheless, the confounding effect of differences in sperm fertilization efficiency due to increased sperm concentration cannot be ruled out as a potential cause of the decrease in fertilization at high sperm concentrations. Similarly, the negative consequences of the artificial means by which gametes were obtained cannot be ignored as a potential artifact in this study.

Sperm availability was not directly evaluated in our field study, and egg quality or size were not controlled. Nevertheless, the higher values of fertilization success in egg cages immersed in biofoam areas compared to non-biofoam areas agrees with previous studies suggesting that gamete suspensions of Pyura praeputialis have an active surfactant capacity that concentrates gametes and developing stages (Castilla et al. 2007). This is supported by the higher numbers of fertilized eggs and eggs with abnormal cleavage patterns in biofoam than in non-biofoam areas during exposure to a single tidal cycle (Fig. 7). This suggests that biofoam may not necessarily be selectively advantageous under certain circumstances. Although our field study only included short trials (see Yund et al. 2007) with the obvious limitations imposed by this type of approach 
(e.g. lack of gamete manipulation, selection of optimal observation times, hydrodynamic conditions), we suggest that biofoam in $P$. praeputialis (1) is linked to spawning and might act as a mechanism that enhances fertilization in this species (Castilla et al. 2007); and (2) enhances settlement on top of or nearby $P$. praeputialis matrices. Moreover, we suggest that fertilization success could also be modified by distance from the spawning site, which is supported by the similar values of fertilization success in the biofoam areas and the coincident reduction in areas without biofoam (Fig. 7).

Our results show a less abrupt reduction in fertilization success in undiluted eggs maintained in a viscous mass than in diluted eggs. The literature suggests that egg longevity in marine free-spawning invertebrates is modified by a combination of endogenous and exogenous factors such as contaminant bacteria and sediment abrasion (Epel et al. 1998, Meidel \& Yund 2001). However, the experiment conducted to assess Pyura praeputialis egg longevity under laboratory conditions was conducted with FSW, without the presence of sediment. Therefore, we tentatively suggest that the egg longevity figures computed from our regression of fertilization success on egg age correspond to the endogenous loss of egg viability. Maximum fertilization success recorded under laboratory conditions was almost twice that recorded under natural conditions using egg cages. This may suggest that our field protocol of exposing eggs to seawater inside plastic cages might have limited sperm access, with a consequent negative effect on fertilization success. However, under such conditions, low fertilization success was accompanied by high levels of developmental failure, which suggests an excess of sperm and polyspermy in biofoam areas. Moreover, similar values for fertilization success when naturally spawned or stripped eggs were immersed in biofoam seawater suggests that the manipulative protocols performed to remove mature eggs had not obscured any unknown behaviour that enhances fertilization success under natural conditions (reviewed by Yund 2000). Therefore, the high levels of developmental failure strongly suggest that our manipulative conditions inside the plastic cages permitted a high rate of contact between eggs and sperm. The laboratory experiments on fertilization were conducted with eggs that were obtained from large-size reared adult specimens. However, the field experiments were conducted with eggs that were obtained from a random pool of naturally spawned or stripped specimens. This may be the origin of differences in egg diameter recorded in our laboratory (Expt 4) and field (Expt 7) experiments. Published evidence for P. stolonifera suggests that fertilization kinetics are strongly affected by egg size, with large eggs requiring less concentrated sperm suspensions than small eggs (Mar- shall et al. 2000). This suggests that the fertilization success recorded under field conditions in our study may have been modulated by the effect of egg size on fertilization success.

The gamete longevity figures, optimal sperm concentrations, and fertilization success under laboratory and field conditions reported in our study may not necessarily represent those present in nature where dilution might be considerably higher. However, our results highlight the importance of synchronized spawning in compensating for the negative consequences of both gamete ageing and dilution in the sea. It has been suggested that gamete longevity is not an important trait in the fertilization ecology of freespawning species because gamete concentrations drop below the critical values required to achieve fertilization long before the gamete lifespan has ended (Levitan et al. 1991, but see Yund 2000, Meidel \& Yund 2001). Therefore, in free-spawning species (e.g. $P$. praeputialis) where spawning involves the epidemic and synchronized shedding of viscous gamete suspensions during low tides, it is expected that gamete longevity and gamete concentration might influence the probability of encounter between gametes.

Unlike similar studies conducted in Pyura chilensis (Manríquez \& Castilla 2005), our manipulated fertilization using strip-spawned gametes of $P$. praeputialis failed to record significant levels of self fertilization, which is in agreement with the published evidence for this species (Clarke et al. 1999). In our study, fertilization failures ended as eggs with no cleavage or with an abnormal cleavage pattern, which were counted as unfertilized eggs or the result of polyspermy respectively. In our experiments where naturally spawned eggs were mixed with spatially related or nonrelated sperm, low levels of fertilization were recorded for spatially related sperm. Further, adjacent gamete masses were considered to be gametes shed by a single specimen; however, unwanted contamination by unrelated allosperm cannot be discounted as false support of self fertilization. Low levels of self fertilization in natural populations of $P$. praeputialis agree with data available for $P$. stolonifera under similar conditions (Marshall 2002). However, occurrence of self fertilization in natural populations of $P$. praeputialis cannot be discounted as an alternative method of fertilization. Thus, self fertilization in hermaphroditic species like $P$. praeputialis would allow it to colonize a new environment and sustain the population under conditions where cross fertilization is not viable such as in the absence of potential mates or in stressful environments (Manríquez \& Castilla 2005). Molecular evidence suggests that $P$. praeputialis probably invaded Antofagasta Bay from the southeastern coast of Australia (Castilla et al. 2004, Astorga et al. 2002). However, 
field experiments have shown that transplanted specimens of $P$. praeputialis can survive and grow well outside the bay (Castilla et al. 2004), suggesting the existence of an unknown mechanism preventing the spread of this alien species out of the bay. Therefore, we suggest that the life history traits exhibited by $P$. praeputialis (e.g. the possible absence of self fertilization, short-lived sperm, synchronous spawning and the short lived tadpole larvae) along with the oceanographic conditions present in Antofagasta Bay (Castilla et al. 2002b, 2004, Escribano et al. 2004) have prevented the spread of this alien species outside the bay. Restricted gamete and larval dispersal, and settlement close to parental individuals increase the potential for inbreeding, leading to a loss in heterozygosity and a reduction in population fitness (Mitton 1993). Available estimations of inbreeding $\left(F_{\mathrm{IS}}\right)$ in natural populations of $P$. praeputialis at different locations around Antofagasta Bay provided positive and negative values for inbreeding, indicating that the occurrence of inbreeding depends on the locality. However, estimations of heterozygosity $(H)$ at the same locations indicated positive values (Astorga et al. 2002, M. Astorga unpubl. data). Regardless of the available genetic evidence, the persistence of natural populations of $P$. praeputialis inside Antofagasta Bay suggests that gene flow through larval and gamete dispersal in this bay is not sufficiently philopatric to produce a heterozygote deficit due to inbreeding depression.

There are few studies on the fertilization behaviour and fertilization success in solitary ascidians inhabiting the rocky intertidal (but see Marshall 2002). However, our results are in agreement with the highest fertilization success obtained when eggs of Pyura stolonifera were incubated with seawater carrying sperm removed from the nearest spawning individual (Marshall 2002), and with records of gamete spawning in wild populations of $P$. praeputialis. The literature indicates that laboratory studies concerning fertilization ecology do not always reflect what happens in the real world (Mead \& Epel 1995). We strongly agree that laboratory settings may impose limitations; however, a portion of our laboratory results is in good agreement with observations of synchronous spawning in nature. Furthermore, our results are supported by the negative consequences of gamete ageing and dilution on fertilization success that has been described for other broadcast spawning marine invertebrates. Our immersion-emersion tank experiment aimed to simulate air exposure during low tides to investigate an environmental variable that is potentially responsible for synchronous gamete release. The synchronous spawning and biofoam formation after air exposure together with the high fertilization success associated with biofoam provide an ecological context for this study: the existence of a mechanism by which the interaction of short-lived gametes in a dilutive environment is maximized. However, in order to be selectively advantageous, the benefits discussed above would need to exceed the cost of an abnormal cleavage pattern that was recorded in eggs exposed to the biofoam.

Acknowledgements. This research was funded by postdoctoral grants (Fondecyt project No. 3020035, 2003-2005; and partially by Fondecyt project No. 1050841, 2005-2008) to P.H.M. We thank M. E. Jara, F. Orellana, Y. Luza and A. Delgado for field and laboratory assistance; M. Lee for correcting the English; and M. Clarke for providing laboratory facilities in Antofagasta. The final version of this manuscript was completed during the conduct of Fondecyt project 1080023 (2008-2011) by P.H.M. Three anonymous referees provided very helpful improvement to the final version of the manuscript. Work carried out in this study complies with the current laws in Chile.

\section{LITERATURE CITED}

André C, Lindegarth M (1995) Fertilization efficiency and gamete viability of a sessile, free-spawning bivalve, Cerastoderma edule. Ophelia 43:215-227

Astorga M, Guiñez R, Ortiz JC, Castilla JC (2002) Variación fenotípica y genética en el tunicado Pyura praeputialis (Heller, 1878) en el área norte de la Bahía de Antofagasta, Chile. Rev Chil Hist Nat 75:515-516

Babcock RC, Bull GD, Harrison PL, Heyward AJ, Oliver JK, Wallace CC, Willis BL (1986) Synchronous spawning of 105 scleractinian coral species on the Great Barrier Reef. Mar Biol 90:379-394

Babcock RC, Mundy CN, Keesing J, Oliver J (1992) Predictable and unpredictable spawning events: in situ behavioural data from free-spawning coral reef invertebrates. Invertebr Reprod Dev 22:213-228

$>$ Baker MC, Tyler PA (2001) Fertilization success in the commercial gastropod Haliotis tuberculata. Mar Ecol Prog Ser 211:205-213

Bingham BL (1997) Light cycles and gametogenesis in three temperate ascidian species. Invertebr Biol 116:61-70

Castilla JC, Collin AG, Meyer CP, Guiñez R, Lindberg DR (2002a) Recent introduction of the dominant tunicate, Pyura praeputialis (Urochordata, Pyuridae) to Antofagasta, Chile. Mol Ecol 11:1579-1584

Castilla JC, Lagos N, Guiñez R, Largier JL (2002b) Embayments and nearshore retention of plankton: the Antofagasta Bay and other examples. In: Castilla JC, Largier JL (eds) Proc Int Symp Linkages and Dynamics of Bays and Open Coast, Santiago, 2000. Ediciones Universidad Católica de Chile, Santiago, p 179-203

Castilla JC, Guiñez R, Caro AU, Ortiz V (2004) Invasion of a rocky intertidal shore by the tunicate Pyura praeputialis in the Bay of Antofagasta, Chile. Proc Natl Acad Sci USA 101:8517-8524

Castilla JC, Manríquez PH, Delgado AP, Gargallo L, Leiva A, Radic D (2007) biofoam retention mechanism to avoid marine larval dispersal. Proc Natl Acad Sci USA 104: 18120-18122

Chia FS, Bickell LR (1983) Spermatogenesis and sperm function. In: Adiyodi KG, Adiyodi RG (eds) Echinodermata. Reproductive biology of invertebrates, Vol 2. John Wiley \& Sons, New York, NY, p 545-620 
Clarke M, Ortiz V, Castilla JC (1999) Does early development of the Chilean tunicate Pyura praeputialis (Heller, 1878) explain the restricted distribution of this species? Bull Mar Sci 65:745-754

Counihan RT, McNamara DC, Souter DC, Jebreen EJ, Preston NP, Johnson CR, Degnan BM (2001) Pattern, synchrony and predictability of spawning of the tropical abalone Haliotis asinina from Heron Reef, Australia. Mar Ecol Prog Ser 213:193-201

Culley TM, Weller SG, Sakai AK (2002) The evolution of wind pollination in angiosperms. Trends Ecol Evol 17:361-369

Epel D, Kaufman M, Xiao L, Kibak H, Patton C (1998) Enhancing use of sea urchin eggs and embryos for cell and developmental studies: method for storing spawned eggs for extended periods. Mol Biol Cell 9:182a

Escribano R, Rosales SA, Blanco JL (2004) Understanding upwelling circulation off Antofagasta (northern Chile): a three-dimensional numerical-modeling approach. Cont Shelf Res 24:37-53

Fan TY, Dai CF (1995) Reproductive ecology of the scleractinian coral Echinopora lamellosa in northern and southern Taiwan. Mar Biol 123:565-572

Gutiérrez JE, Lay JE (1965) Observaciones biológicas en la población de Pyura chilensis, Molina 1782, en Antofagasta (Urochordata, Ascidiacea, Pyuridae). Estud Oceanol 1:1-9

Harrison PL, Babcock RC, Bull GD, Oliver JK, Wallace CC, Willis BL (1984) Mass spawning in tropical reef corals. Science 223:1186-1189

Havenhand JN (1991) Fertilization and the potential for dispersal of gametes and larvae in the solitary ascidian Ascidia mentula Müller. Ophelia 33:1-15

- Levitan DR (1998a) Does Bateman's principle apply to broadcast-spawning organisms? Egg traits influence in situ fertilization rates among congeneric sea urchins. Evolution 52:1043-1056

Levitan DR (1998b) Sperm limitation, gamete competition, and sexual selection in external fertilizers. In: Birkhead TR, Møller AP (eds) Sperm competition and sexual selection. Academic Press, San Diego, CA, p 175-217

Levitan DR, Sewell MA, Chia FS (1991) Kinetics of fertilization in the sea urchin Strongylocentrotus franciscanus: interaction of gamete dilution, age, and contact time. Biol Bull (Woods Hole) 181:371-378

Manríquez PH, Castilla JC (2005) Self-fertilization as an alternative mode of fertilization in the solitary tunicate Pyura chilensis. Mar Ecol Prog Ser 305:113-125

Manríquez PH, Hughes RN, Bishop JDD (2001) Age-dependent loss of fertility in water-borne sperm of the bryozoan Celleporella hyalina. Mar Ecol Prog Ser 224:87-92

Marshall DJ (2002) In situ measures of spawning synchrony and fertilization success in an intertidal, free-spawning invertebrate. Mar Ecol Prog Ser 236:113-119

Marshall DJ, Styan CA, Keough MJ (2000) Intraspecific covariation between egg and body size affects fertilisation kinetics in free-spawning marine invertebrates. Mar Ecol Prog Ser 195:305-309

Marshall DJ, Semmens D, Cook C (2004) Consequences of spawning at low tide: limited gamete dispersal for a rockpool anemone. Mar Ecol Prog Ser 266:135-142

McCartney MA, Lessios HA (2002) Quantitative analysis of gametic incompatibility between closely related species of neotropical sea urchins. Biol Bull (Woods Hole) 202: 166-181

Mead KS, Epel D (1995) Beakers versus breakers: how fertilisation in the laboratory differs from fertilisation in nature. Zygote 3:95-99

> Meidel SK, Yund PO (2001) Egg longevity and time-integrated fertilization in a temperate sea urchin (Strongylocentrotus droebachiensis). Biol Bull (Woods Hole) 201: $84-94$

Mitton JB (1993) Theory and data pertinent to the relationship between heterozygosity and fitness. In: Thornhill NW (ed) The natural history of inbreeding and outbreeding. The University of Chicago Press, Chicago, IL, p 17-41

- Oliver J, Babcock R (1992) Aspects of the fertilization ecology of broadcast spawning corals: sperm dilution effects and in situ measurements of fertilization. Biol Bull 183:409-417

Pemberton AJ, Hughes RN, Manríquez PH, Bishop JDD (2003) Efficient utilization of very dilute aquatic sperm: sperm competition may be more likely than sperm limitation when eggs are retained. Proc R Soc Lond B (Suppl) 270:223-226

Pérez-Portela R, Bishop JDD, Davis AR, Turon X (2009) Phylogeny of the families Pyuridae and Styelidae (Stolidobranchiata, Ascidiacea) inferred from mitochondrial and nuclear DNA sequences. Mol Phylogenet Evol 50: $560-570$

Piñones A, Castilla JC, Guiñez R, Largier JL (2007) Temperaturas superficiales en sitios cercanos a la costa en la Bahía de Antofagasta (Chile) y centros de surgencia adyacentes. Cienc Mar 33:37-43

Strathmann MF (1987) General procedures. In: Strathmann MF (ed) Reproduction and development of marine invertebrates of the northern Pacific coast. University of Washington Press, Seattle, WA, p 3-43

Watson GJ, Williams ME, Bentley MG (2000) Can synchronous spawning be predicted from environment parameters? A case study of the lugworm Arenicola marina. Mar Biol 136:1003-1017

Williams ME, Bentley MG (2002) Fertilization success in marine invertebrates: the influence of gamete age. Biol Bull (Woods Hole) 202:34-42

Yund PO (2000) How severe is sperm limitation in natural populations of marine free-spawners? Trends Ecol Evol 15: $10-12$

> Yund OP, Murdock K, Johnson SL (2007) Spatial distribution of ascidian sperm: two-dimensional patterns and short vs. time-integrated assays. Mar Ecol Prog Ser 341:103-109 